\title{
PERCEPÇÃO DE PROFESSORES DE FÍSICA E ENGENHARIA ACERCA DE CONCEPÇÕES NÃO CIENTÍFICAS DE CIRCUITOS ELÉTRICOS EM ARRANJOS TEÓRICO-EXPERIMENTAIS
}

DOI: 10.37702/2175-957X.COBENGE.2021.3587

Thaiana Catarina Melo de Oliveira - tcmo@discente.ifpe.edu.br Instituto Federal de Pernambuco

Rua Arraial do Bom Jesus 1056

55296-544 - Garanhuns - PE

Mariana Eduarda Ferreira Xavier - mefx@discente.ifpe.edu.br Instituto Federal de Educação Ciência e Tecnologia de Pernambuco Rua José de Alencar 28

55299-445 - Garanhuns - PE

WILKER VICTOR DA SILVA AZEVÊDO - wilker.azevedo@garanhuns.ifpe.edu.br IFPE Instituto Federal de Educação Ciência e Tecnologia de Pernambuco Avenida dos Mascates 195

55292-279 - Garanhuns - PE

Resumo: A persistência de algumas concepções não científicas em estudantes ao redor de todo o mundo provoca questionamentos acerca da origem destas concepções, trazendo à tona a necessidade de estudar sobre o papel dos professores de circuitos elétricos e a relação entre a abordagem didática convencional e a constância de determinadas concepções. Dessa forma, o presente trabalho objetiva, através de um questionário aplicado a quatro professores que ensinam circuitos elétricos em diversas turmas do ensino médio/técnico e/ou superior, estudar o conhecimento dos professores acerca da existência e persistência de algumas concepções não científicas entre os seus alunos, com o intuito de cooperar com o estado da arte e tornar os docentes mais conscientes da existência das múltiplas concepções não científicas, para que estes possam propor abordagens mais diversificadas e ativas com a finalidade de sanar a persistência destas concepções. Como resultados, observou-se que os docentes apresentam certo conhecimento da existência de algumas concepções não científicas, porém não citam diretamente ao longo do questionário nenhum dos modelos abordados, evidenciando assim, que há a possibilidade de eles 
presenciarem no dia-a-dia a existência de pensamentos comuns entre os alunos, contudo sem associá-los a determinado modelo de concepção não científica. Ademais, foi possível visualizar uma carência na junção dos ensinos teórico e prático, sendo esta motivada por uma possível lacuna na formação dos docentes relacionada ao ensino convencional.

Palavras-chave: Concepções não científicas. Circuitos elétricos. Professores. 


\title{
C COBENCE \\ 28 a 30 de SETEMBRO \\ PERCEPÇÃO DE PROFESSORES DE FÍSICA E ENGENHARIA ACERCA DE CONÇEPÇÕES NÃO CIENTÍFICAS DE CIRCUITOS ELÉTRICOS EM ARRANJOS TEÓRICO-EXPERIMENTAIS
}

\section{INTRODUÇÃO}

A construção de um conceito pode ser prejudicada por raciocínios e ideias vinculadas a saberes de outras áreas, significados não generalizáveis, cotidianos e/ou falsas ideias, da linguagem escrita/visual dos indivíduos. Isto pode dificultar a aprendizagem, contudo é passível de diagnóstico e apreciação. Em Física ou Engenharia, ações teóricas ou empíricas, ao docente implica a responsabilidade de compreender as concepções e buscar alternativas ao Ensino. Em Circuitos Elétricos, concepções são estudadas há décadas, em que ideias semelhantes em estudantes de diversas regiões são observadas, uma possível relação da abordagem pelos docentes. McDermott (1991) afirma:

\begin{abstract}
Algumas concepções não científicas são de tal maneira sérias que podem tornar o ensino significativo uma tarefa impossível, mesmo quando o desempenho na solução de problemas quantitativos não é afetado. Mesmo que uma dificuldade de raciocínio ou de conceitos predominantemente esteja presente entre os estudantes, ela pode estar latente e consequentemente não aparente, nem para eles, nem para o professor. Algumas concepções não científicas podem ser atribuídas a uma experiência limitada. Outras podem resultar de falsas interpretações da experiência prévia. Nestes casos, a concepção não científica pode adquirir a solidez de uma crença (McDermott, 1991, pp. 307-308).
\end{abstract}

Nota-se que é imprescindível aos professores desenvolver conhecimento sobre a existência de concepções não científicas entre os estudantes para que possam propor estratégias eficazes na reorganização da compreensão dos alunos. Neste escopo, um mapeamento acerca das concepções não científicas aponta e dá nomenclatura a algumas que aparecem com mais frequência, sendo registrados na literatura (McDERMOTT, 1991; GAIGHER, 2014; MOODLEY e GAIGHER, 2019; AZEVÊDO e GITIRANA, 2020): o modelo atenuação, aquele no qual a corrente diminui ao longo de um circuito elétrico conforme 'passa' pelos dispositivos presentes no circuito; o modelo fonte de corrente constante, onde a fonte de tensão no circuito é entendida como uma fonte de corrente constante, fornecendo assim, corrente constante independentemente do circuito que a ela for conectado; o modelo de regra empírica, no qual quanto mais distante a lâmpada estiver da fonte de alimentação, menor será o seu brilho; o modelo sequencial, onde o estudante analisa o circuito em termos de 'antes' ou 'após' a passagem da corrente em um determinado ponto e uma alteração no início do circuito afeta apenas elementos que vêm depois; o modelo de raciocínio local, o qual significa que, durante uma alteração em um ponto do circuito, se ignora os impactos na mudança de grandezas no restante dos pontos deste circuito; o modelo curto-circuito, onde se ignoram fios que interconectam pontos do circuito e que não possuem componentes conectados; o modelo circuito paralelo, o qual sugere que o aumento do número de resistores conectados em paralelo resulta no aumento da resistência equivalente; o modelo de raciocínio morfológico, retratando superposição semântica entre significados da geometria e da topologia elétrica do circuito.

Dupin e Joshua (1987) afirmaram que os modelos de fonte de corrente constante e de atenuação são os mais persistentes, e atribuem esta persistência de alguns modelos aos efeitos do ensino. Um exemplo claro é que, ao enfatizar que a corrente é constante em 
um circuito com dispositivos conectados em série, os professores podem, mesmo que sem intenção, estarem promovendo o desenvolvimento do modelo de fonte de corrente constante. Suryadi, Kusairi e Husna (2020) apontam diferentes concepções não científicas entre professores e estudantes, aparecendo o modelo de regra empírica em muitos estudantes do ensino médio, além do modelo fonte de corrente constante e curto-circuito nos alunos de graduação, sugerindo para o último caso a possibilidade de experimentação. Ainda, estes autores acenam que docentes e alunos podem ter dificuldade em diferenciar os conceitos de corrente e energia na análise de alguns cenários.

Tendo em vista a importância de o professor estar ciente das concepções não científicas mais comuns entre os discentes, ele deve conceber e analisar cenários para o planejamento de suas aulas. Nisto, deve conhecer a demanda teórico-profissional na formação de engenheiros (aperfeiçoando o processo de ensino-aprendizagem), refletir sobre situações de aprendizagem, compreender a capacidade analítica demandada na análise de problemas que situam as concepções. Assim, o trabalho tem o objetivo de investigar a interpretação de alguns professores que atuam em cursos de Engenharia sobre potenciais respostas de estudantes. O contexto "Perguntas sobre Respostas" expõe um estudo de caso em caráter exploratório e pode permitir avaliar entendimentos e propostas de abordagem pelos docentes. Um questionário foi elaborado enquadrando concepções, incluindo aquelas relacionadas a registros de representação semiótica, pressupostos topológicos e empíricos (domínios tecnológicos experimentais). Os resultados visam trazer um overview relacionado à compreensão dos docentes sobre as dificuldades discentes, ideias, concepções e como devem ser tratadas face o espectro e realidade de cada professor. Discussões admitem a possibilidade de incorporar o debate sobre as concepções não científicas e a idealização de situações de aprendizagem ainda na formação docente.

\section{METODOLOGIA}

A revisão bibliográfica acerca de concepções não científicas em Circuitos Elétricos balizou o desenvolvimento da metodologia utilizada no trabalho, o qual culminou em uma estrutura dividida em algumas fases. A maior parte dos estudos sobre concepções não científicas são voltadas para classificar ou "corrigir" concepções de alunos, enquanto poucos pesquisadores se concentram no papel do professor, nas suas próprias concepções. A pesquisa desenvolvida por Gaigher (2014) foi pioneira na busca para entender a visão dos professores acerca das concepções não científicas. Em seu percurso metodológico, evita-se o confronto com os docentes sobre seus conhecimentos acerca das concepções não científicas, avaliando então como estes interpretam as respostas de estudantes. Tal estratégia é incorporada neste trabalho, porém com um contexto expandido das concepções e experimentação. De modo complementar, admite-se a concepção dos problemas e sua análise sob o ponto de vista dos registros de representação semiótica (DUVAL \& MORETTI, 2012) e dos domínios tecnológicos (AZEVÊDO \& GITIRANA, 2020), em que versam sobre os recursos da escrita algébrica, da língua natural nas respostas, das imagens e diagramas, dos dispositivos experimentais e sua forma de exploração. Aqui se considera que a apreensão dos objetos da Física remete a uma apreensão conceitual, contudo, ela ocorre e torna possível a interpretação do sujeito sobre os objetos através de representações semióticas. As representações semióticas são produções constituídas pelo emprego de signos pertencentes a um sistema de representações que tem inconvenientes próprios de significação e de funcionamento (DUVAL \& MORETTI, 2012). Sendo assim, no intuito da comunicação, elemento essencial ao pensamento cognitivo, as representações semióticas permitem comunicar um saber de diversas formas diferentes, auxiliando a apreensão conceitual através de um domínio destas operações. 
A proposta global, situada neste contexto, assume quatro fases: (1) compreender dificuldades sobre o raciocínio científico de professores; (2) avaliar o planejamento de aulas destes professores; (3) enquadrar de maneira integrada a teoria de Circuitos Elétricos sob o viés dos registros de representação e domínios tecnológicos; (4) avaliar a reorganização dos professores sobre suas concepções e sobre a forma de redimensionar suas aulas para promover a superação das dificuldades conceituais dos estudantes.

Foi desenvolvido um questionário com 7 (sete) situações-problema, que abordam os modelos de concepções indicados na seção anterior, além de dificuldades vinculadas a imagens de montagens físicas. Os docentes nesta fase atuam no contexto da Educação Profissional Tecnológica (EPT), participaram voluntariamente do estudo de caso exploratório, integram contextos escolares com alunos de diferentes perfis socioeconômicos, sendo que dois deles possuem bacharelado em engenharia elétrica e outros dois são licenciados em física. Três possuem titulação máxima de mestrado e um de doutorado (um dos licenciados em Física). Os colaboradores atuam ou atuaram no ensino médio integrado para formação de profissionais da área técnica e na educação superior (Engenharia Elétrica), atuando em instituições federais EPT de três estados. Ainda em relação aos participantes, as experiências acadêmicas como docente na área variavam de 5 a 19 anos.

Para coleta de informações eles foram questionados sobre como os seus alunos responderiam determinadas questões de circuitos elétricos (APÊNDICE). O instrumento de pesquisa foi aplicado de maneira remota e assíncrona aos professores e as respostas foram analisadas, buscando entender se apresentaram conhecimento da existência destas concepções e que estratégias poderiam ser abordadas para ajudar os estudantes a compreenderem determinados cenários/conceitos.

As questões desenvolvidas foram arquitetadas de forma que as concepções não científicas estudadas fossem abordadas, admitindo a exploração do Registro da Língua Natural, do Registro Icônico (imagens), do Registro Algébrico e o Domínio Tecnológico na forma de referência icônica (imagem de um recurso empírico). Em cada questão foram incluídas de maneira proposital no mínimo duas concepções em cada uma das respostas em forma de alternativa. Em alguns cenários uma única alternativa era passível de expor mais de uma concepção a depender da interpretação do professor. Ademais, o formato torna factível a perspectiva de que os professores possam expor a existência de alguma concepção não científica que não foi indicada ao longo da revisão bibliográfica ou mesmo no contexto das expectativas do problema, resultado de suas experiências em sala de aula.

As quatro primeiras questões do instrumento de pesquisa apresentaram problemas sobre circuitos elétricos simples em corrente contínua com situações-problema cuja análise requeria de modo implícito e/ou explícito conhecimento científico sobre tensão, corrente e resistência e potência elétrica como grandezas basilares, curto-circuito e circuito aberto como conceitos em desdobramento e de leis básicas como a Lei de Ohm, as leis de Kirchhoff (Tensões, Correntes) ou mesmo métodos mais robustos decorrentes destes (Método das Tensões de Nó, Método das correntes de Malha). Os professores responderam a 3 perguntas para cada uma dessas questões: "Qual das alternativas incorretas os alunos tenderiam a escolher?", "Por que você acredita que eles provavelmente a escolheriam?" e "Como você ajudaria os seus alunos a desenvolverem o entendimento correto sobre esta questão?". Em cada uma das alternativas incorretas foi trabalhado ao menos um dos modelos de concepções não científicas e o objetivo destas perguntas é observar se o professor apresenta conhecimento da existência desta concepção e como ele trabalha isto com os estudantes, para que desta forma possamos entender a relação entre a persistência destes modelos entre os alunos e o processo de ensino (dificuldades e estratégias). Esse mapeamento é essencial na primeira fase do processo de seleção e 
aplicação metodológica devido à importância do papel do professor como agente que pode tornar possível uma abordagem ativa com o intuito de mitigar esta persistência.

A quinta questão do instrumento aborda o modelo de raciocínio morfológico e pede para que o professor identifique qual ou quais dos circuitos os alunos diriam ser equivalentes topologicamente incluídas variações morfológicas do mesmo conteúdo conceitual (passível análise algébrica ou da topologia elétrica com conceitos como nó elétrico e malha). Também são realizadas as seguintes perguntas: "Por que você acredita que eles provavelmente a escolheriam?" e "Como você ajudaria os seus alunos a desenvolverem o entendimento correto sobre esta questão?", com o intuito de analisar quais ligações ou operações topológicas os professores observam serem mais difíceis de os alunos visualizarem em diagramas não convencionais (no sentido da exploração didática). Este aspecto é essencial uma vez que as aplicações profissionais do saber científico muitas vezes não seguem o padrão visual de livros e de exemplos construídos com simetria e "retangularização" visual das representações adotadas em sala de aula. Por fim, as duas últimas questões trabalham dificuldades relacionadas a protótipos reais de circuitos elétricos, com aplicações usando recursos de laboratório (protoboard, fonte DC, resistores), cuja pesquisa delineou transformações e saberes empíricos.

\section{$3 \quad$ RESULTADOS E DISCUSSÕES}

Preservando o anonimato dos participantes, pseudônimos são utilizados em referência (Quadro 1). Devido ao enfrentamento da pandemia da COVID-19, o questionário foi criado e aplicado de forma online. Além de aplicado a licenciados em física e bacharéis em engenharia elétrica, deve ser estendido a médio prazo a licenciandos e pesquisadores. Em todas as instituições dos participantes existem laboratórios de eletricidade/eletrônica ou congênere. Todos os que responderam são do gênero masculino (resultado aleatório neste ponto de análise dado que não era este critério de seleção uma vez que o formulário fora encaminhado também a professoras). Dada a variedade de perfis e experiências, esperavase também heterogeneidade na conjecturação de hipóteses, respostas e propostas.

Quadro 1 - Perfil dos docentes participantes.

\begin{tabular}{|l|l|l|l|l|l|l|}
\hline Pseud. & Formação & $\begin{array}{l}\text { Tempo de } \\
\text { docência }\end{array}$ & Atuação & $\begin{array}{l}\text { Atuação com } \\
\text { Circuito Elétricos }\end{array}$ & $\begin{array}{l}\text { Perfil da(s) } \\
\text { disciplina(s) }\end{array}$ & $\begin{array}{l}\text { Titulação } \\
\text { máxima }\end{array}$ \\
\hline Atos & $\begin{array}{l}\text { Licenciatura } \\
\text { em Física }\end{array}$ & 11 anos & $\begin{array}{l}\text { Curso Técnico } \\
\text { e Bacharelado }\end{array}$ & $\begin{array}{l}\text { Ensino Médio / } \\
\text { Técnico }\end{array}$ & Teórica & Mestrado \\
\hline Bento & $\begin{array}{l}\text { Licenciatura } \\
\text { em Física }\end{array}$ & 11 anos & $\begin{array}{l}\text { Curso Técnico } \\
\text { e Bacharelado }\end{array}$ & $\begin{array}{l}\text { Ensino Médio / } \\
\text { Técnico }\end{array}$ & Teórica & Doutorado \\
\hline Celso & $\begin{array}{l}\text { Engenharia } \\
\text { Elétrica }\end{array}$ & 5 anos & $\begin{array}{l}\text { Curso Técnico } \\
\text { e Bacharelado }\end{array}$ & $\begin{array}{l}\text { Ensino Médio / } \\
\text { Técnico, Eng. Elétrica }\end{array}$ & $\begin{array}{l}\text { Teórica e } \\
\text { Experimental }\end{array}$ & Mestrado \\
\hline Delfim & $\begin{array}{l}\text { Engenharia } \\
\text { Elétrica }\end{array}$ & 19 anos & $\begin{array}{l}\text { Curso Técnico } \\
\text { e Bacharelado }\end{array}$ & Engenharia Elétrica & Teórica & Mestrado \\
\hline
\end{tabular}

Fonte: Organizado pelos autores.

As análises das respostas obtidas são orientadas segundo apreciação do conteúdo no contexto teórico-conceitual e empírico de cada questão, inferências e associações ao estado da arte, avaliando-se representações no conteúdo dos problemas e referenciado nas respostas dos participantes. É avaliado se os professores demonstram conhecimento de forma clara de cada uma das concepções não científicas abordadas, buscando-se entender a forma com a qual o professor ensina determinados conceitos, a permanência ou potencial superação das concepções não científicas passíveis de ocorrência aos alunos.

As possíveis respostas das quatro primeiras questões, juntamente com quais concepções não científicas elas podem apresentar, são mostradas no Quadro 2. 
Quadro 2 - Concepções não científicas incluídas em alguns problemas explorados.

\begin{tabular}{|c|c|c|c|c|}
\hline Alternativa & Questão 1 & Questão 2 & Questão 3 & Questão 4 \\
\hline A & $\begin{array}{c}\text { Atenuação da } \\
\text { corrente e modelo } \\
\text { de regra empírica }\end{array}$ & $\begin{array}{c}\text { Modelos de raciocínio } \\
\text { local e de fonte de } \\
\text { corrente constante }\end{array}$ & $\begin{array}{c}\text { Modelo curto- } \\
\text { circuito }\end{array}$ & $\begin{array}{c}\text { Modelo circuito } \\
\text { paralelo }\end{array}$ \\
\hline B & $\begin{array}{c}\text { Atenuação da } \\
\text { corrente e modelo } \\
\text { de regra empírica }\end{array}$ & Modelo sequencial & Modelo sequencial & $\begin{array}{c}\text { Modelo fonte de } \\
\text { corrente constante }\end{array}$ \\
\hline C & Alternativa correta & Alternativa correta & Alternativa correta & Alternativa correta \\
\hline D & ------- & Modelo sequencial & --- \\
\hline \multicolumn{2}{r|}{ Fonte: Organizado pelos autores. } \\
\hline
\end{tabular}

Na primeira e segunda questões do instrumento foram explorados o registro icônico (imagem de circuito com associações lâmpada/resistor) e a língua natural na indicação de respostas, além dos conceitos de associação série, em paralelo, grandezas e leis básicas.

Por meio da análise das justificativas dos professores à escolha da alternativa pelos alunos na questão 1 (Tabela 1), nota-se que a maioria manifesta saber da existência do modelo de atenuação da corrente ou de regra empírica. Há referências a ideias de posição relativa ("resistor localizado após a lâmpada", Atos), de redução da corrente ("corrente diminui", Celso), de posição e energia dissipada ("dissipação viria depois", Bento). Para Delfim, os itens $A$ e B poderiam ser escolhidos pelos discentes embora não tenha feito uma descrição de motivo para tal, referindo-se apenas às informações descritas no enunciado. Estas não são evidências suficientes de que os professores entendam a concepção.

Tabela 1 - Sumário das respostas dos professores à primeira questão.

\section{Alternativa que os alunos tenderiam a escolher? \\ Por que acha que eles a escolheriam?}

\begin{tabular}{cc}
\hline & $\begin{array}{l}\text { Muitos estudantes são levados a } \\
\text { acreditar que a resistência à corrente } \\
\text { comece após ela passar pela lâmpada } \\
\text { no esquema do circuito 1, tendo em } \\
\text { vista que nessa disposição o resistor } \\
\text { ficar localizado após a lâmpada. }\end{array}$ \\
\hline
\end{tabular}

Bento A $\quad \begin{aligned} & \text { Acreditariam que a dissipação } \\ & \text { viria depois }\end{aligned}$

\begin{tabular}{lll}
\hline Celso & A & $\begin{array}{l}\text { Pensa-se que a corrente diminui } \\
\text { quando passa por algum elemento } \\
\text { resistivo. }\end{array}$ \\
\hline
\end{tabular}

Delfim A, B

\section{Como ajudar para entendimento correto?}

O entendimento correto é mostrar que a corrente é algo que se forma simultaneamente em todo 0 circuito devido a todos os seus componentes e suas disposições.

O brilho depende da ddp e corrente que a lâmpada está submetida. A organização do circuito deve auxiliar para obtermos essa informação.

Explicando o significado de corrente elétrica e seu comportamento em um ramo.

Penso que de 10 alunos que Reforçando o entendimento sobre erraram, 5 marcariam A e 5 leis Kirchhoff e lei de Ohm e marcariam B. cálculo de potência.

Fonte: Organizado pelos autores.

No circuito da Questão 1 são apresentados componentes ligados em série (mesma malha elétrica), o qual resulta que a corrente nos componentes é a mesma, a tensão é distribuída proporcionalmente à resistência (compreendamos a lâmpada passível de modelagem como resistor). Logo, o brilho da lâmpada seria o mesmo nos dois casos dada a equivalência, independentemente da posição relativa entre a lâmpada e o resistor.

Quanto a maneiras de ajudar o entendimento científico, Atos destaca a formação simultânea da corrente, o que sugere essa percepção do gradiente de carga. Partir desta grandeza também é algo proposto por Celso, em que lança ainda o conceito auxiliar de 
"ramo". A observação sobre apenas uma grandeza deve ser avaliada uma vez que o brilho está associado com a potência dissipada pela lâmpada $(p=i . v)$. Por sua vez, Bento faz referência a duas grandezas basilares (tensão, corrente), o que implica o uso do registro algébrico ou da língua natural para caracterizá-las em cada caso e, a partir daí, discorrerse sobre a potência. Note ainda citação à "organização", em que interpretamos como uma característica topológica do circuito (tipo de associação, de ligações). Delfim incorpora ao conteúdo do seu discurso (na língua natural) referência direta às Leis básicas (Kirchhoff, Ohm) e ao registro algébrico ("cálculo da potência"). Apesar de formações diferentes, os licenciados em física (Atos, Bento) e os engenheiros eletricistas (Celso, Delfim) priorizam a abordagem conceitual, sem referências a soluções experimentais ou de manipulação de componentes, comportamento percebido em pesquisa na literatura (GAIGHER, 2014).

$\mathrm{Na}$ questão 2 são apresentados dois circuitos com lâmpadas e resistores associados de forma mista e, com a inserção de mais uma lâmpada ao circuito (no ponto marcado), é questionada a alteração nos brilhos das duas lâmpadas já presentes (APÊNDICE). Em ambas as lâmpadas há uma diminuição do brilho. Quanto às respostas obtidas (Tabela 2), verifica-se que Atos e Bento dizem que os alunos tenderiam à escolha da alternativa $A$, que indica presença dos modelos de raciocínio local e de fonte de corrente constante, contudo, nenhum demonstra conhecimento da existência destes modelos quando respondem o porquê de os alunos selecionarem esta alternativa. No entanto, ambos expuseram saber da existência de uma outra concepção não científica que aparentemente é comum entre os alunos destes dois professores: a crença de que a lâmpada não possui resistência interna ou de que ela não iria interferir na resistência total do circuito. Isto retrata uma lacuna: a falta do relacionamento da propriedade "resistência elétrica" com a representação de modelos para dispositivos físicos reais no ensino disciplinar.

Tabela 2 - Sumário das respostas dos professores à segunda questão.

\begin{tabular}{ccc}
\hline Docente & $\begin{array}{c}\text { Alternativa que os } \\
\text { alunos tenderiam } \\
\text { a escolher? }\end{array}$ & $\begin{array}{c}\text { Por que acha que eles a } \\
\text { escolheriam? }\end{array}$ \\
\hline Atos & A & $\begin{array}{l}\text { Os estudantes seriam levados a } \\
\text { acreditar que o dispositivo "lâmpada" } \\
\text { não interfere na resistência do circuito. }\end{array}$ \\
\hline
\end{tabular}

Como ajudar para
entendimento correto?

Mostrar que a lâmpada é um dispositivo que exerce resistência sobre o circuito.

Entender que associação de lâmpada (resistência) em série aumenta a Bento A $\quad \begin{aligned} & \text { Pois não levariam em conta a } \\ & \text { resistência interna da lâmpada L3. }\end{aligned}$ resistência equivalente do circuito e consequentemente diminui a corrente. Diminuindo a corrente, diminui a potência (brilho) na lâmpada.

A corrente passaria pelo L1 da Adicionando mais uma resistência na mesma maneira que no primeiro malha, acorrente total cairia em relação circuito. Mas em L2 ela atravessou L3 antes.

ao primeiro, diminuindo a potência em todos os (componentes do) circuito.

Porque no enunciado da questão, Delfim B está afirmado que L3 está em série Reforçando leis de Kirchhoff e lei com L2 e não cita L1

de Ohm, potência elétrica.

Fonte: Organizado pelos autores.

Para Celso e Delfim, a alternativa B seria escolhida pelos estudantes. Há descrição do modelo sequencial na resposta de Celso, expondo saber do modelo mesmo que ele não o cite diretamente. Este docente lança o conceito auxiliar de malha elétrica e, embora explique as mudanças a partir da inserção da lâmpada L3 (Figura 1) quando questionado sobre como ajudar para o entendimento correto (semelhante ao proposto por Bento), isto não se refere a uma maneira adotada no ensino e sim um desdobramento analítico. Três dos quatro participantes não expuseram entendimento conceitual da concepção. Delfim 
atribui a escolha da alternativa ao fato de que na questão se enfatiza apenas a associação das lâmpadas L3 e L2, induzindo assim os estudantes a acreditarem que há uma diminuição do brilho da lâmpada L2, enquanto L1 permanece com o mesmo brilho, ou seja, apontando a necessidade de se observar a influência da língua natural na formulação do problema, apesar da concatenação deste registro de representação com a forma icônica (diagrama).

Figura 1 - Circuito elétrico da questão 2 após a inclusão da lâmpada L3.
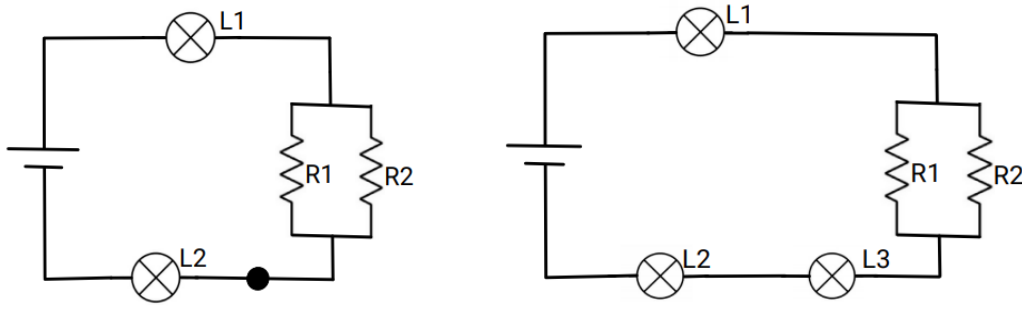

Fonte: Organizado pelos autores.

Todos os professores propõem novamente uma abordagem teórica com o objetivo de auxiliar os estudantes na compreensão desta questão, citando que explicariam sobre as grandezas elétricas e como se comportam neste circuito. Delfim cita mais uma vez a ideia de reforçar leis primordiais no estudo de circuitos elétricos (leis de Kirchhoff e lei de Ohm), enquanto Bento e Celso efetuam explicação científica da potência como função da corrente.

$\mathrm{Na}$ terceira questão os modelos sequencial e de curto-circuito foram abordados nas alternativas $B$ e $A$, respectivamente (APÊNDICE). O registro algébrico é tratado na forma de expressão para cálculo da resistência equivalente vista dos terminais da fonte. Os resultados estão apresentados na Tabela 3. Apenas Celso observa uma possível presença do modelo curto-circuito na concepção dos alunos, de forma indireta, quando descreve o princípio desta concepção: "Como nesse condutor a resistência é zero, não fará diferença". Os outros professores acreditam que seus alunos tenderiam a assinalar a alternativa $\mathrm{B}$ e todos mostram determinado conhecimento acerca desta concepção não científica típica.

Tabela 3 - Sumário das respostas dos professores à terceira questão.

\begin{tabular}{ccc} 
Docente & $\begin{array}{c}\text { Alternativa que os } \\
\text { alunos tenderiam } \\
\text { a escolher? }\end{array}$ & \multicolumn{1}{c}{$\begin{array}{c}\text { Por que acha que eles a } \\
\text { escolheriam? }\end{array}$} \\
\hline Atos & B & $\begin{array}{l}\text { Os estudantes que melhor desenvolveram o } \\
\text { conhecimento sobre circuitos elétricos seriam } \\
\text { levados a responder a letra b. Isso porque a } \\
\text { figura, como nos livros, devido sua disposição, } \\
\text { levaria o estudante imaginar que a ponte } \\
\text { entre os pontos Ae B influenciaria apenas no } \\
\text { resistor de resistência R3 e a corrente } \\
\text { passaria pelo resistor de resistência R2. }\end{array}$ \\
\hline
\end{tabular}
$\begin{array}{ll}\text { Bento } & \text { B } \quad \begin{array}{l}\text { Pela lei do nó, induz o aluno a subtender } \\ \text { que a corrente se dividiria em duas. }\end{array}\end{array}$

\section{Como ajudar para entendimento correto?}

Mostraria para eles que os pontos A e B são os mesmos das "quinas" do circuito.

Entender que a corrente sempre procura o caminho de menor resistência. Neste caso o fio liso. Deixando as resistências R2 e R3 em curto.

Essa conexão estabelece um percurso sem resistência. Logo, toda a corrente passará por ela. Um curto "elimina" os elementos em paralelo.

Reforçaria associação de resistores
Delfim

\section{A}

B
Mesmo com o condutor ligado, a corrente deve percorrer as mesmas resistências. Como nesse condutor a resistência é zero, não fará diferença.
Eles tenderiam a pensar que o fio anularia o efeito do resistor R3 que está à direita.

\section{Fonte: Organizado pelos autores.}


Há referências às ideias de posição do resistor ("a ponte entre os pontos $A$ e $B$ influenciaria apenas no resistor de resistência R3", Atos; "o fio anularia o efeito do resistor R3 que está à direita", Delfim) e da circulação de corrente elétrica de forma sequencial ("a corrente passaria pelo resistor de resistência R2", Atos; "a corrente se dividiria em duas", Bento), evidenciando assim o conhecimento dos professores sobre algumas concepções, acenando porém elementos de aprendizagem importantes pelos docentes licenciados em física: a forma com que os livros abordam disposição dos componentes (citado por Atos) e a lei dos nós, desdobramento da Lei das Correntes de Kirchhoff (referenciado por Bento).

Como forma de ajudar os alunos no entendimento da questão, observa-se a proposta da ênfase do conceito de "nó elétrico", referido pelo professor Atos como "quinas" do circuito (disposição dos ramos em $90^{\circ}$ ) - uma referência icônica morfológica do desenho, sendo este elemento (ponto energético de conexão entre dois componentes), importante para caracterizar ligações e o entendimento elementar da distribuição de corrente.

A proposta feita por Bento é mais detalhada em relação a um modelo mental "Entender que a corrente sempre procura o caminho de menor resistência. [...]". Celso extrapola a percepção conceitual da corrente elétrica no curto-circuito $\left(i=\lim _{R \rightarrow 0} V / R\right)$ : "Essa conexão estabelece um percurso sem resistência. Logo, toda a corrente passará por ela. [...]" . As colocações destes docentes podem de certa forma contribuir com a persistência do modelo sequencial entre os alunos, por levarem a concretizar o pensamento de que 'a corrente segue no circuito por partes, buscando o componente a seguir', quando há um construto científico a partir dos modelos atômicos que expõe seu estabelecimento simultâneo em todo o circuito por variação instantânea da carga $(i=d q / d t)$. Nenhum docente sugeriu a discussão do conceito científico de Resistência Elétrica (ou da lei de Ohm).

Três dos docentes na questão 3 revelam uma concepção de corrente como instância líquida/fluido, referenciada por verbos utilizados (passar, procurar, percorrer). Ainda, existe a relação algébrica da corrente elétrica com a resistência de componentes na associação em paralelo (Lei das Correntes de Kirchhoff) foi referenciada indiretamente apenas por Delfim. A maioria expõe algumas ideias e explicações não generalizáveis, a possibilidade de uma concepção não científica adquirir a solidez de uma crença (McDERMOTT, 1991).

Desenvolver alternativas a uma melhor compreensão das concepções sequencial e curto-circuito torna-se, de fato, uma demanda célere uma vez reconhecido o papel docente, sua interpretação e a possibilidade de desenvolver novas alternativas ao ensino, superando inclusive suas próprias concepções não científicas. Pesquisas exibem a dificuldade de boa parte de estudantes calouros de engenharia elétrica quanto ao raciocínio sequencial (SMAILL et al., 2012) e de alunos do ensino médio sobre curto-circuito (PESMAN e ERYILMAZ, 2010), algo cuja manutenção em atividades empíricas no ensino médio, técnico ou no ensino superior pode implicar em desdobramentos à segurança individual e coletiva.

$\mathrm{Na}$ quarta questão foi explorada a análise das concepções não científicas circuito paralelo e modelo fonte de corrente constante, sendo questionado sobre como as leituras nos amperímetros $A_{1}$ e $A_{2}$ mudariam com a remoção de um resistor $R_{2}$ (Figura 2).

Figura 2 - Considerações com recorrência ao registro algébrico sobre o circuito elétrico da questão 4

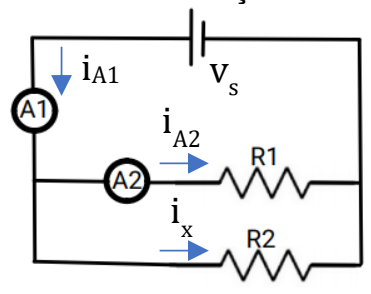

$$
\begin{gathered}
\mathrm{i}_{\mathrm{A} 1}=\left(\frac{1}{\mathrm{R} 1}+\frac{1}{\mathrm{R} 2}\right) \mathrm{v}_{\mathrm{S}} ; \quad \mathrm{i}_{\mathrm{A} 1}=\frac{1}{\mathrm{R} 1} \mathrm{v}_{\mathrm{S}} \\
\mathrm{i}_{\mathrm{A} 1}^{\prime}<\mathrm{i}_{\mathrm{A} 1} \\
\mathrm{i}_{\mathrm{A} 2}{ }^{\prime}=\mathrm{i}_{\mathrm{A} 1}{ }^{\prime}=\mathrm{i}_{\mathrm{A} 2}=\mathrm{v}_{\mathrm{S}} / \mathrm{R} 1
\end{gathered}
$$

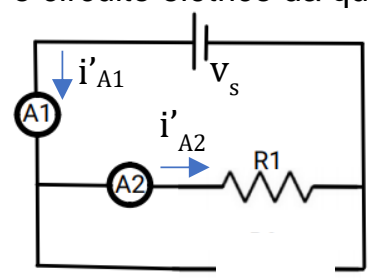

Fonte: Organizado pelos autores. 
O estudante poderia entender que ao remover do circuito um resistor, qualquer que seja, a resistência equivalente vista pela fonte reduz, e, portanto, aumenta a corrente elétrica (uma das formas de manifestação do modelo de concepção de circuito paralelo). De outra forma, pode expor que a corrente em $\mathrm{A}_{1}$ permanece a mesma, independentemente da alteração feita no circuito ("a mesma corrente 'vinda' da fonte"), e, portanto, $A_{2}$ tende a aumentar, já que a corrente total não seria mais 'dividida' entre os dois ramos (concepção 'fonte de corrente constante'). Na tabela 4 há um sumário das respostas dos docentes.

Tabela 4 - Sumário das respostas dos professores à quarta questão.

\begin{tabular}{|c|c|c|c|}
\hline Docente & $\begin{array}{l}\text { Alternativa que os } \\
\text { alunos tenderiam } \\
\text { a escolher? }\end{array}$ & $\begin{array}{c}\text { Por que acha que eles a } \\
\text { escolheriam? }\end{array}$ & $\begin{array}{l}\text { Como ajudar para } \\
\text { entendimento correto? }\end{array}$ \\
\hline Atos & 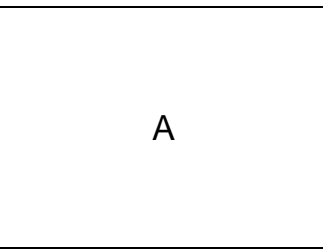 & $\begin{array}{l}\text { Como removeu-se um resistor do circuito, a } \\
\text { resistência equivalente diminuiria e ambas } \\
\text { as correntes aumentariam. Ou seja. Os } \\
\text { estudantes pensam que a corrente que } \\
\text { passa pelo amperímetro A2 sempre depende } \\
\text { da corrente que passa pelo amperímetro A1. }\end{array}$ & $\begin{array}{l}\text { Mostrar para eles que a } \\
\text { corrente no Resistor R1 só } \\
\text { depende da resistência R1 e } \\
\text { da FEM da fonte, tendo em } \\
\text { vista que essa última não } \\
\text { possui resistência interna. }\end{array}$ \\
\hline Bento & B & Por saber que alguma mudança ocorre. & $\begin{array}{l}\text { Pensar sempre na lei de Ohm } \\
\text { e analisar cada caminho. }\end{array}$ \\
\hline Celso & A & $\begin{array}{l}\text { Se remover uma resistência do circuito, } \\
\text { fica mais fácil de a corrente passar. } \\
\text { Aumenta a corrente. }\end{array}$ & $\begin{array}{l}\text { Resolvendo um circuito } \\
\text { específico. }\end{array}$ \\
\hline Delfim & A & $\begin{array}{l}\text { Retirando um resistor, aumenta a } \\
\text { corrente elétrica. }\end{array}$ & $\begin{array}{l}\text { Reforçando leis de } \\
\text { Kirchhoff, lei de Ohm e } \\
\text { associação de resistores. }\end{array}$ \\
\hline
\end{tabular}

Fonte: Organizado pelos autores.

Apenas Bento destaca a alternativa $B$, porém não expõe conhecimento da possível presença do modelo de fonte de corrente constante em sua explicação. Os outros três professores descrevem o princípio do modelo de circuito paralelo, sendo que apenas Atos propõe um construto científico em detalhes sobre como ajudaria no entendimento da questão, algo citado por Bento e Delfim apenas no contexto geral das leis de circuitos. Celso propõe auxiliar os estudantes resolvendo "um circuito específico", contudo sem detalhes explicitados. Esta questão foi baseada em situação proposta por Gaigher (2014), com objetivo semelhante ao aqui indicado. Em contrapartida, no trabalho de Gaigher todos os professores propõem a utilização da prática para auxiliar o entendimento dos alunos, o que não foi observado no contexto dos docentes desta pesquisa, os quais atuam na EPT.

O raciocínio morfológico foi abordado na questão 5 (APÊNDICE), com síntese na Tabela 5. A diferença entre topologia e geometria de circiuitos é abordada nesta questão, buscando identificar se os professores conseguem identificar quais ligações ou operações topológicas os alunos apresentam maiores dificuldades em visualizar. Os circuitos majoritariamente presentes nas respostas dos professores sobre quais os alunos diriam não serem equivalentes topologicamente ao circuito principal, foram os circuitos II, III e IV. O circuito II foi projetado com o intuito de identificar dificuldades com rotação e alternação de ramos, e, observa-se na descrição do porquê os alunos escolheriam este circuito que os professores Atos e Celso conseguem identificar e descrever bem esta dificuldade típica. O circuito III apresenta uma presença da dificuldade de visualização relacionada a falsa seriação, porém, nenhum dos três professores que o escolheram explicaram o porquê desta escolha, como era esperado. Já o circuito IV mostra a dificuldade com a visualização de uma associação mista geometricamente diferente da apresentada no circuito principal, e, novamente, embora três dos professores tenham escolhido este circuito, nenhum relatou 0 porquê da escolha ou qual seria a dificuldade encontrada pelo estudante neste circuito. 
Tabela 5 - Sumário das respostas dos professores à quinta questão.

\begin{tabular}{|c|c|c|c|}
\hline Docente & $\begin{array}{l}\text { Circuitos que os } \\
\text { alunos escolheriam? }\end{array}$ & $\begin{array}{c}\text { Por que acha que eles a } \\
\text { escolheriam? }\end{array}$ & $\begin{array}{c}\text { Como ajudar para } \\
\text { entendimento correto? }\end{array}$ \\
\hline Atos & II, III e IV & $\begin{array}{l}\text { Sabemos que todos são iguais. Eles } \\
\text { escolheriam principalmente o Il devido a } \\
\text { ordem em que os resistores se apresentam. } \\
\text { Se fizermos um esquema de corrente } \\
\text { no esquema II, essa "passaria primeiro" } \\
\text { pelos resistores R3 e R4 para passar } \\
\text { em R2. Ocontrário aconteceria no esquema } \\
\text { inicial apresentado. Na verdade, essa } \\
\text { ordem é apenas um costume didático. }\end{array}$ & $\begin{array}{l}\text { Atualmente, após averiguar } \\
\text { trabalhos de colega, falaria a } \\
\text { respeito dos nós. }\end{array}$ \\
\hline Bento & | e |l & $\begin{array}{l}\text { Pois há uma grande dificuldade de } \\
\text { visualizar associação em paralelo } \\
\text { diferente da forma usual. }\end{array}$ & $\begin{array}{l}\text { Trabalhando as diferentes } \\
\text { possibilidades de representar } \\
\text { uma associação em paralelo. }\end{array}$ \\
\hline Celso & II, III e IV & $\begin{array}{l}\text { pela troca inversa do } \mathrm{r} 2 \text { com os } \mathrm{r} 3 \mathrm{e} \\
\text { r4. }\end{array}$ & $\begin{array}{l}\text { Explicitar os pontos elétricos } \\
\text { do circuito. Mostrar a conexão } \\
\text { do resistor r3 com r1. }\end{array}$ \\
\hline Delfim & III e IV & $\begin{array}{l}\text { Alguns errariam por conta do } \\
\text { desenho. }\end{array}$ & $\begin{array}{l}\text { Reforçaria associação de } \\
\text { resistores. }\end{array}$ \\
\hline
\end{tabular}

Fonte: Organizado pelos autores.

Apenas um dos professores selecionou o circuito I como o circuito que os estudantes diriam ser diferente topologicamente do principal. Este apresenta um falso paralelismo e o professor Bento consegue explicar de forma clara que os estudantes apresentam uma grande dificuldade de visualizar associação em paralelo diferente da forma usual. Como diz Azevêdo e Gitirana (2016), "a geometria de um circuito é determinada pela forma como os componentes são posicionados no espaço enquanto a topologia é estabelecida pela maneira como os componentes estão conectados uns aos outros".

Ademais, a presença do modelo de raciocínio morfológico entre os estudantes acarreta dificuldades em montagens de protótipos reais de circuitos elétricos, o que pôde ser visível nas repostas dos professores às questões 6 e 7 (APÊNDICE). O professor Celso demonstra, de forma indireta, a presença do modelo de raciocínio morfológico como culpada das dificuldades mais persistentes vivenciadas no dia-a-dia quando diz que uma das maiores dificuldades é "montagem correta a partir do papel", evidenciando assim que a dificuldade em montagens físicas a partir dos circuitos elétricos construídos com simetria em sala de aula é uma dificuldade real dos estudantes. Um deles, quando questionado sobre quais dificuldades ele acredita serem mais persistentes, responde que "as maiores dificuldades são entender que a corrente é algo que se forma no circuito, que a associação de resistores não depende apenas do desenho (fila indiana = associação em série, paralelismo no desenho = associação em paralelo) e a influência de cada dispositivo em todo o circuito" (Atos), mostrando assim conhecimento da existência de algumas concepções não científicas, como o modelo de raciocínio local e de raciocínio morfológico, mesmo que indiretamente. Além disso, o docente reconhece não estar familiarizado ao uso do protoboard, enfatizando certa lacuna da relação entre teoria e prática experimental.

\section{CONCLUSÕES}

A pesquisa permitiu observar que os docentes apresentam pouco conhecimento sobre a existência de concepções não científicas bastante difundidas na literatura, o que pode ser visível em várias das questões abordadas. A expectativa da identificação de algumas das concepções pelos professores foi frustrada. Embora haja o conhecimento de como os estudantes tendem a pensar sobre determinadas questões, eles podem não ter total compreensão da origem destes raciocínios. 
Observa-se também em algumas respostas uma possível contribuição com a persistência de algumas concepções não científicas entre os estudantes, como por exemplo o modelo sequencial, através da forma como repassam o conteúdo, podendo, mesmo que de forma não intencional, enfatizar uma determinada maneira comum, embora equivocada, de os estudantes analisarem circuitos elétricos.

As questões do relatório foram desenvolvidas de forma que em todas as alternativas incorretas houvesse a possível existência de pelo menos uma concepção não científica como motivo para a assinalar, entretanto, apenas com esta escolha não poderíamos deduzir que o professor apresenta conhecimento da existência da concepção não científica. Por isto, os professores foram perguntados do porquê que os alunos assinalariam aquela opção, e a partir desta resposta é que se torna possível analisar se de fato há um conhecimento da existência daquela concepção pelo professor ou se a suposição da escolha dos alunos por aquela alternativa seria por algum outro motivo, como a existência de uma concepção não científica menos difundida na literatura ou percepção nova.

Como o relatório foi aplicado de forma remota aos professores, não foi possível a análise de outros registros de representação nas respostas dos docentes, como registro algébrico (por meio de equações) ou icônico (via representação de diagramas). Ademais, observa-se também que, além de os professores evidenciarem nas últimas questões uma carência do ensino prático associado ao ensino teórico, nenhum deles propôs utilizar a prática como forma de auxiliar os estudantes no entendimento de alguma das questões ou de conceitos subliminares da teoria (nó, ramo, malha), provável lacuna na formação quanto ao ensino convencional na formação de alguns docentes, distanciando a teoria do ensino com recursos experimentais físicos. Outra importante contribuição se mostra na incursão, pelos docentes, de um feedback sobre alternativas de ensino, cujos maiores contributos se expuseram na avaliação das situações-problema envolvendo o registro icônico (imagem), o algébrico, e as referências à língua natural.

Prospecta-se uma futura reunião entre os docentes participantes do questionário para a realização de entrevistas estruturadas e da reflexão conjunta. É relevante uma maior conscientização dos docentes quanto à existência das múltiplas concepções não científicas dos discentes, ações colaborativas, bem como a utilização de uma abordagem mais diversificada como vias à superação da persistência destas concepções.

\section{Agradecimentos}

Ao IFPE, pelo apoio e concessão da bolsa ao longo do projeto, e, especialmente, aos professores colaboradores, que se dispuseram a contribuir com a pesquisa realizada.

\section{REFERÊNCIAS}

AZEVÊDO, W. V. S.; GITIRANA, V. Dificuldades geométricas e topológicas de estudantes em circuitos resistivos: Problema da física e/ou da matemática?. In: Encontro Nacional de Didática da Geometria e das Grandezas e Medidas (EnDiGGraM), 2016, Recife. Anais EnDiGGraM. Disponível em: encurtador.com.br/bdmxS. Acesso em: 01 maio. 2020.

AZEVÊDO, W. V. S.; GITIRANA, V. Multidimensional Perspective about Resistors Association in Electric Circuits: Part I - Investigating Non-Scientific Conceptions and Instructional Materials. Brazilian Journal of Development, Curitiba, v. 6, n. 6, p. 41610-41632, 2020.

DUPIN, J. J., JOSHUA, S. Conceptions of French pupils concerning electric circuits: Structure and evolution. Journal of Research in Science Teaching, v. 24, p. 791-806, 1987. 
Duval, R. Registros de representação semiótica e funcionamento cognitivo do pensamento. Tradução por: Moretti, M. T. Revemat: Revista eletrônica de Educação Matemática. elSSN 1981-1322. Florianópolis, v. 07, n. 2, p.266-297, 2012.

GAIGHER, E. Questions about answers: probing teachers' awareness and planned remediation of learners' misconceptions about electric circuits. African Journal of Research in Mathematics, Science and Technology Education, v. 18, n. 2, p. 176-187, 2014.

MCDERMOTT, L.C. Millikan Lecture 1990: What we teach and what is learned-Closing the gap. The American Journal of Physics, v. 59, n. 4, p. 301-315, 1991.

MOODLEY, Kimera; GAIGHER, Estelle. Teaching electric circuits: Teachers' perceptions and learners' misconceptions. Research in Science Education, v. 49, n. 1, p. 73-89, 2019.

PESMAN, Haki; ERYILMAZ, Ali. Development of a Three-Tier Test to Assess Misconceptions About Simple Electric Circuits. The Journal of Educational Research, v. 103, p. 208-222, 2010.

SMAILL et al. An Investigation into the Understanding and Skills of First-Year Engineering Students. IEEE Transactions on Education, v. 55, n. 1, p. 29-35, 2012.

SURYADI, A.; KUSAIRI, S.; HUSNA, D. A. Comparative Study of Secondary School Students' and Pre-Service Teachers' Misconception about Simple Electric Circuit. Jurnal Pendidikan Fisika Indonesia, v. 16, n. 2, p. 111-121, 2020.

\section{PERCEPTION OF PHYSICS AND ENGINEERING TEACHERS ABOUT MISCONCEPTIONS OF ELECTRICAL CIRCUITS IN THEORETICAL-EXPERIMENTAL ARRAGEMENTS}

Abstract: The persistence of some misconceptions in students around the world causes questions about the origin of these conceptions, bringing up the need to study the role of teachers who teach Electrical Circuits and the relationship between the conventional didactic approach and the constancy of certain conceptions. Thus, the main aim of work is, through a questionnaire applied to four teachers who teach electrical circuits in different classes of high school / technical and / or university, to study the knowledge of teachers about the existence and persistence of some misconceptions among their students, in order to cooperate with the state of the art and make teachers more aware of the existence of multiple misconceptions, so that they can propose more diverse and active approaches in order to remedy the persistence of these conceptions. As a result, it was observed that the teachers present some knowledge of the existence of some misconceptions, however, they do not directly explain any of the models approached throughout the questionnaire, thus evidencing is the possibility that they witness the day-to-day existence of common thoughts among students, however without associating them with a certain model of misconception. In addition, it was possible to see a shortage in the combination of theoretical and practical teaching, which was motivated by a possible gap in the training of teachers related to conventional education.

Keywords: Misconceptions. Electric circuits. Teachers. 


\section{APÊNDICE - SITUAÇÕES-PROBLEMA DO INSTRUMENTO DE PESQUISA}

Questão 1. Comparando o brilho da lâmpada (L) nos circuitos 1 e 2, tem-se que a lâmpada:

a) Apresenta maior brilho no circuito 1. (Modelos de atenuação e de regra empírica considerando a corrente com o sentido convencional)

b) Apresenta maior brilho no circuito 2. (Modelos de atenuação e de regra empírica considerando a corrente com o sentido real)

c) Em ambos os circuitos apresenta o mesmo brilho. (Alternativa correta)

*As tensões nas fontes de ambos os circuitos são iguais.

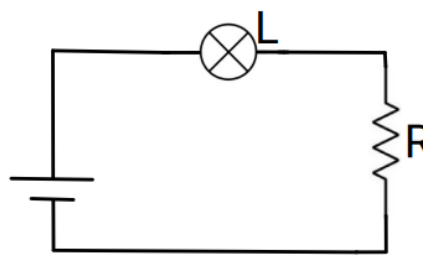

Circuito 1

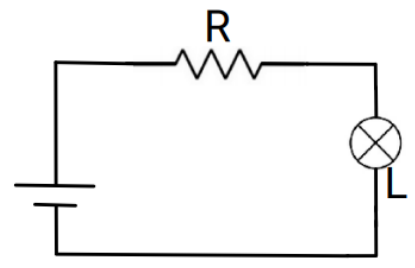

Circuito 2

Questão 2: Ao adicionar uma lâmpada $\mathrm{L}_{3}$ no ponto marcado da Figura 1 (em série com $\mathrm{L}_{2}$, assim como é visto na Figura 2), como os brilhos das lâmpadas $L_{1}$ e $L_{2}$ mudariam? Considerar as três lâmpadas iguais.

a) Permaneceria o mesmo brilho em ambas. (Modelos de raciocínio local e de fonte de corrente constante)

b) $\mathrm{Em} \mathrm{L}_{2}$ diminuiria e em $\mathrm{L}_{1}$ permaneceria o mesmo brilho. (Modelo sequencial considerando a corrente com o sentido convencional)

c) Diminuiria em ambas. (Alternativa correta)

d) $\mathrm{Em} \mathrm{L}_{1}$ diminuiria e em $\mathrm{L}_{2}$ permaneceria o mesmo brilho. (Modelo sequencial considerando a corrente com o sentido real)

*As tensões nas fontes de ambos os circuitos são iguais.

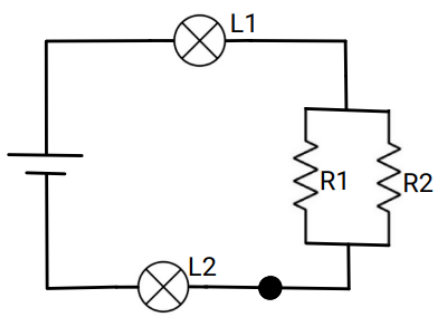

Figura 1

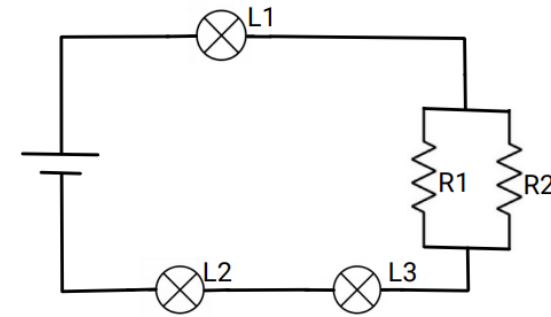

Figura 2

Questão 3: No circuito da Figura 1, a resistência equivalente é $R_{\text {eq. }}=R_{1}+\frac{R_{2} \cdot R_{3}}{R_{2}+R_{3}}$. Supondo que seja realizada uma ligação entre os pontos $\mathrm{A}$ e $\mathrm{B}$, conforme mostra a Figura 2, qual seria a resistência equivalente do circuito?

a) Permaneceria a mesma. (Modelo curto-circuito)

b) $R_{\text {eq. }}=R_{1}+R_{2}$. (Modelo sequencial)

c) $\mathrm{R}_{\text {eq. }}=\mathrm{R}_{1}$. (Alternativa correta)

*As tensões nas fontes de ambos os circuitos são iguais. 


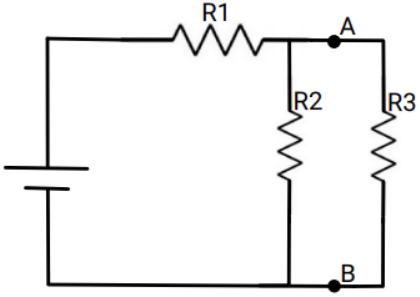

Figura 1

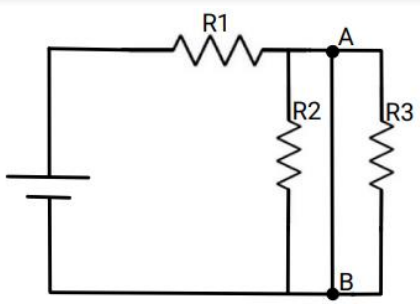

Figura 2

Questão 4: Supondo que o resistor $R_{2}$ da figura abaixo seja removido do circuito, como as leituras nos amperímetros $\mathrm{A}_{1}$ e $\mathrm{A}_{2}$ mudariam?

a) Ambas aumentariam. (Modelo circuito paralelo)

b) $\mathrm{A}_{1}$ permaneceria a mesma e $\mathrm{A}_{2}$ aumentaria. (Modelo fonte de corrente constante)

c) $\mathrm{A}_{1}$ diminuiria e $\mathrm{A}_{2}$ permaneceria a mesma. (Alternativa correta)

${ }^{*}$ As tensões nas fontes de ambos os circuitos são iguais.

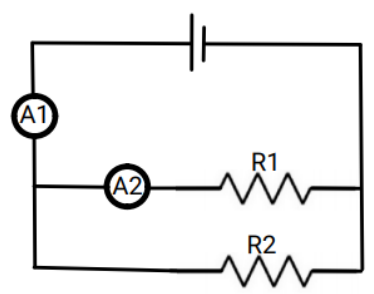

\section{Questão 5:}

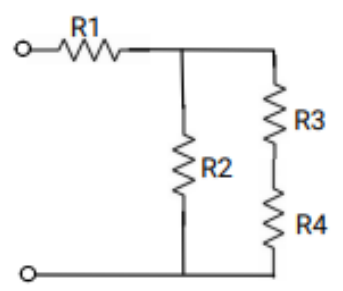

A partir do circuito da figura acima, identifique qual(quais) dos circuitos abaixo não apresenta $(m)$ a mesma topologia.

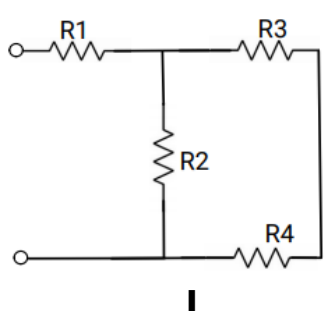

I

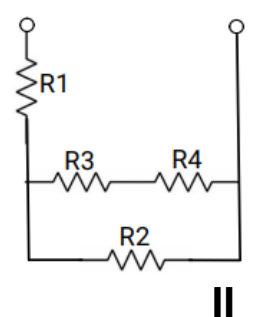

II

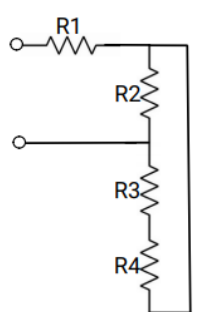

III

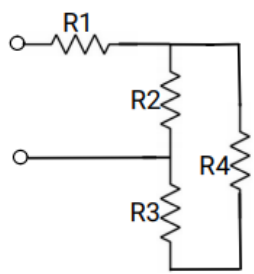

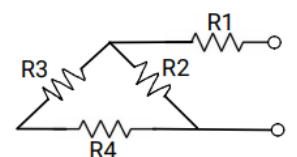

IV
V

- A questão aborda o modelo de raciocínio morfológico, sendo a escolha do circuito I um possível indício da dificuldade de visualização com circuitos que indicam falso paralelismo, o circuito II pode indicar dificuldade com rotação do circuito e com mudança na posição dos ramos, o circuito III demonstra falsa seriação. O circuito IV mostra uma dificuldade com a visualização da associação mista em um formato diferente, e por fim, o circuito $\vee$ exibe uma possível confusão com a associação em delta. 
Questão 6: Se o aluno visualiza a montagem do circuito abaixo e é solicitada, a partir de resolução teórica, a tensão sobre os resistores conectados entre as colunas 20 e 35 do protoboard (os resistores mais à direita do protoboard), qual a maior dificuldade do mesmo na sua percepção?

PS.: Considera-se que o terminal positivo da fonte DC é conectado à entrada Va do protoboard (jumper vermelho) e o terminal negativo à entrada de aterramento (jumper preto).

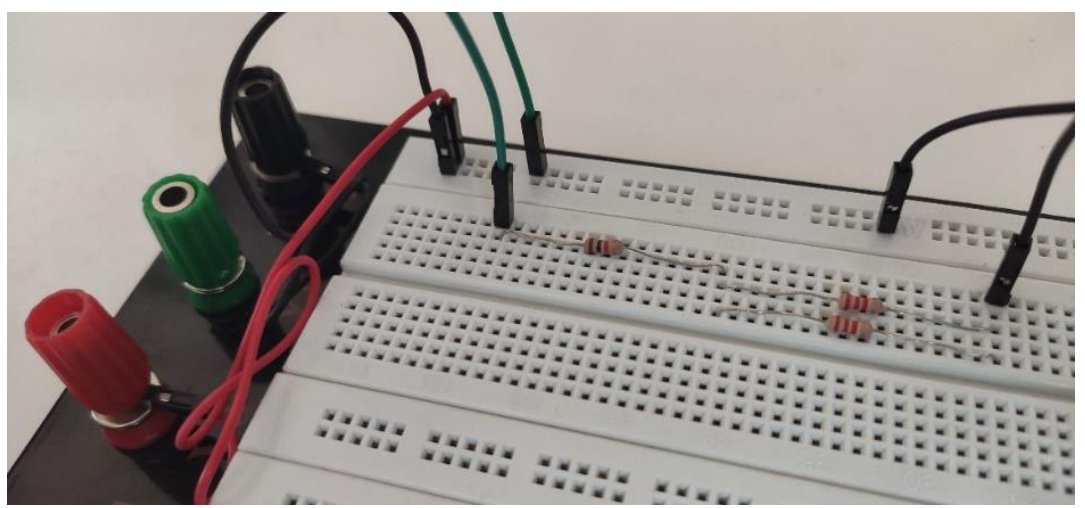

a) Obter os valores dos resistores a partir do código de cores.

b) Analisar as ligações topológicas entre os resistores (série, paralelo).

c) Analisar a conexão da fonte DC ao circuito.

d) Realizar o cálculo do divisor de tensão.

e) Outras...

Questão 7: Considerando o circuito abaixo, qual tensão os alunos obteriam sobre o resistor mais abaixo do circuito? Porque você acredita que eles provavelmente escolheriam esta alternativa?

PS.: Considera-se que o terminal positivo da fonte DC é conectado à entrada Va do protoboard (jumper vermelho) e o terminal negativo à entrada de aterramento (jumper preto).

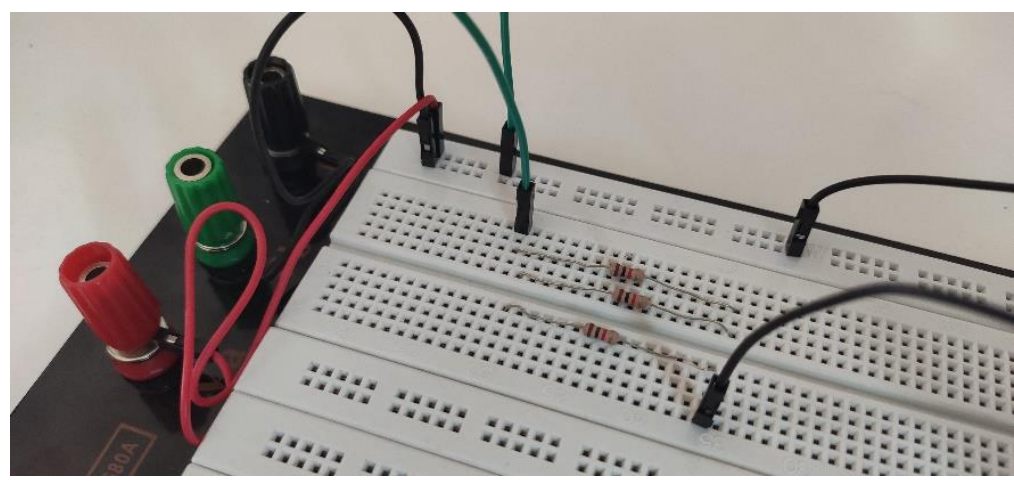
a) $V_{R}=V_{F}$.
b) $V_{R}=\frac{V_{F}}{3}$.
c) $V_{R}=0$. 